Review

\title{
Biomanufacturing by in vitro biosystems containing complex enzyme mixtures
}

\author{
Chun You ${ }^{\mathrm{a}, *}$, Y.-H. Percival Zhang ${ }^{\mathrm{a}, \mathrm{b}, \mathrm{c}}$ \\ a Tianjin Institute of Industrial Biotechnology, Chinese Academy of Sciences, 32 West 7th Avenue, Tianjin Airport Economic Area, Tianjin 300308, People's \\ Republic of China \\ b Biological Systems Engineering Department, Virginia Tech, 304 Seitz Hall, Blacksburg, VA 24061, USA

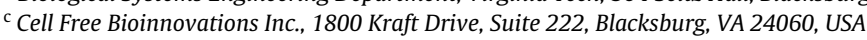

\section{A R T I C L E I N F O}

\section{Article history:}

Received 20 April 2016

Received in revised form

18 September 2016

Accepted 24 September 2016

Available online xxx

\section{Keywords:}

In vitro biosystems

Biomanufacturing

Microbial fermentation

Complex enzyme mixtures

\begin{abstract}
A B S T R A C T
Microbial fermentation is the current predominant biomanufacturing platform. However, it suffers from low production yields, slow reaction rates, and scaling-up challenges. In vitro enzymatic biosystems are emerging to expand the traditional biotechnological mode by utilizing more than three enzymes for manufacturing the desired product from cheap substrate. In the past few years, numerous proofs of the concept of in vitro biosystems containing complex enzyme mixtures from different groups worldwide have inspired the development of these platforms for biomanufacturing, these biosystems show advantages such as near-theoretical product yields, faster reaction rates, reduced interference from toxic compounds, and unprecedented level of engineering. In this review, several examples of in vitro systems are presented to illustrate these advantages and possible solutions to overcome the remaining challenges are discussed. The continuing decrease in enzyme cost and improvements in enzyme engineering techniques will make in vitro biosystems a comparable biomanufacturing platform for microbial fermentation in the near future.
\end{abstract}

(c) 2016 Elsevier Ltd. All rights reserved.

\section{Contents}

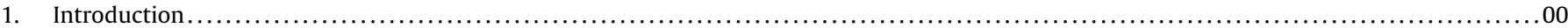

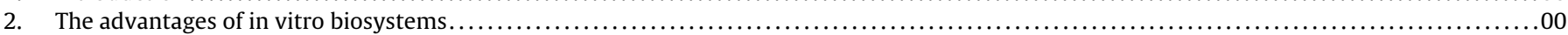

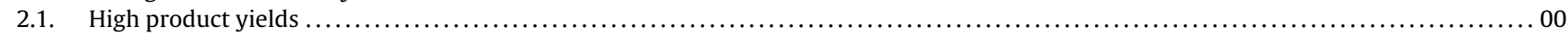

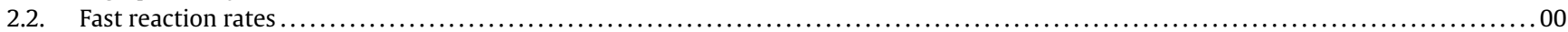

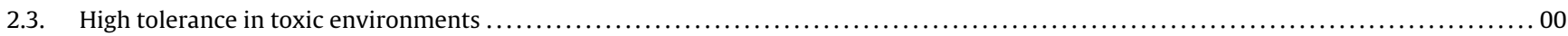

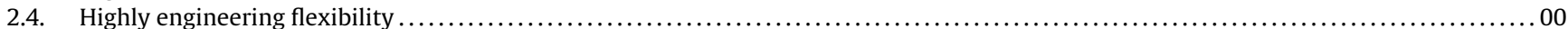

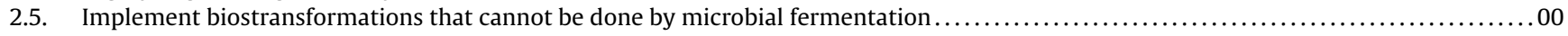

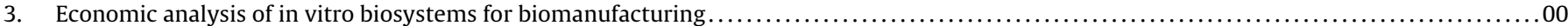

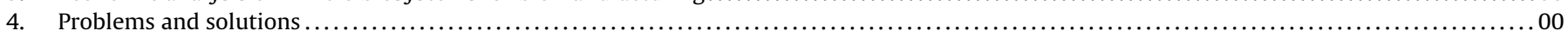

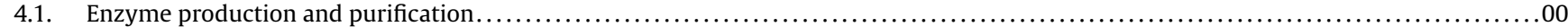

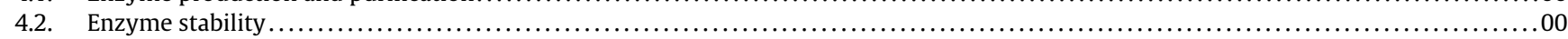

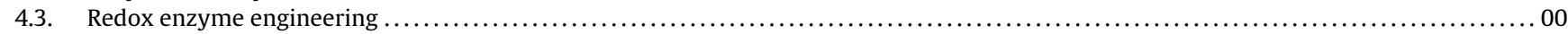

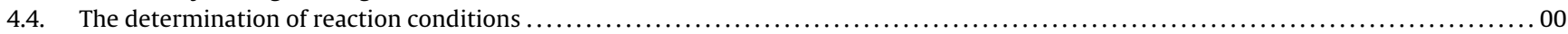

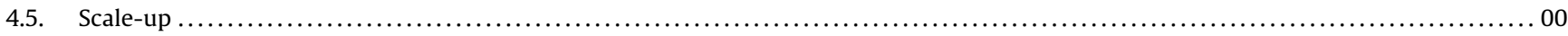

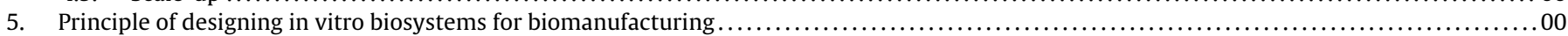

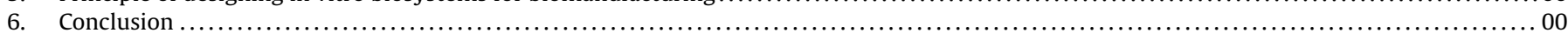

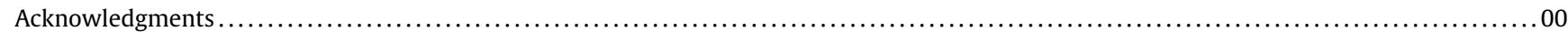

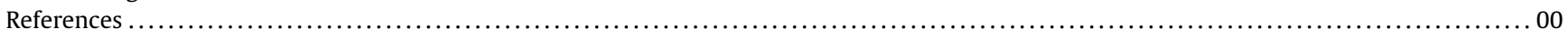

\footnotetext{
* Corresponding author.

E-mail address: you_c@tib.cas.cn (C. You).
} 


\section{Introduction}

In vitro biosystems contain a number of purified/partially purified enzymes (usually more than 4) and coenzymes in a single reaction vessel for the production of desired products through complicated biochemical reaction pathways. At the beginning, in vitro biosystems were used by scientists to study the basic biological mechanisms, and some of these scientists have received Nobel Prizes for their pioneering work, including Eduard Buchner for discovering yeast extract (nonliving yeast) that can convert glucose to ethanol [1], Arthur Harden and Hans von Euler-Chelpin for the investigation of the fermentation of enzymes and fermentative sugar[2], Otto Warburg for his discovery of the nature and mode of action of the respiratory enzymes [3], Carl and Gerty Cori for the discovery of the course of the catalytic conversion of glycogen [4,5], Hans Krebs for the discovery and elucidation the citric acid cycle [6], Melvin Calvin for the investigation ofcarbon dioxide assimilation in plants [7], Nirenberg for the elucidation the genetic codon [8]. In vitro biotransformations based on enzymes became popular manufacturing tools about 50 years after the discovery of enzymes, from one-enzyme biotransformations to multi-enzyme biotransformations. The most famous instance is glucose isomerase, which is being used in the manufacture of high-fructose corn syrup (HFCS) [9]. Other important manufacturing developments for enzymes include the use of thermostable polymerase to amplify DNA [10], the use of immobilized nitrile hydratases to produce acrylamide [11], and the use of amylases and amyloglucosidases to produce glucose [12]. In the current century, some in vitro biosystems containing more than 4 enzymes were constructed to implement much more complicated reactions for the production of high-cost pharmaceuticals (e.g., heparin and protein drug) [13] to low-cost biocommodities (e.g., hydrogen and alcohols) [14,15].

Because of the limited availability of fossil fuels and climate changes, a revolutionary shift from using fossil to using sustainable resources is occurring in this century, inducing substantial efforts in industrial biotechnology for manufacturing [16,17]. Living wholecell fermentation is the predominant biomanufacturing platform to help meet the world's increasing need for fuels, pharmaceuticals, and commodity chemicals [18]. For example, penicillin has been industrially produced by fungi for decades [19], saving millions of lives; most of the amino acids are produced by living microorganisms [20]. This platform has some advantages, for example, cells can harness the power of evolution by directed evolution and adaption to increase the product yield and product separation cost can be low because the cells are larger than products. However, fermentation processes also have inherent limitations imposed by cells. For example, a significant part of input resources is used for cell proliferation, and not for the production of the desired compounds, and many side pathways inside cells direct the metabolic flux to yield undesired compounds, resulting in low production yield. Moreover, substrate uptake and product excretion are slowed down by cell membranes, resulting in slow reaction rates. The unwieldy complexity of cells makes rational design unpredictable and difficult to engineer. Many fermentation processes can work in the laboratory, but transferring them to industrial scale is not economically feasible [21-24]. Because of the distinctive advantages of in vitro biosystems compared to the microbial fermentation systems, in vitro biosystems emerge as a new biomanufacturing platform to cope with the complexity and limitations imposed by the cells $[25,26]$. In this review, we focus on discussing some examples of in vitro biosystems for biomanufacturing to specify the major advantages compared to microbial fermentation, economic analysis and design principle of these systems, as well as the problems of applying these systems for industrial scale production and possible solutions.

\section{The advantages of in vitro biosystems}

We use several examples of in vitro biosystems to specify the advantages of these manufacturing systems, including high product yield, fast reaction rate, high tolerance of toxic environments, and high engineering flexibility, etc.

\subsection{High product yields}

High product yields can be achieved in in vitro biosystems by eliminating the competition of side pathways for intermediates and resource loss for sustaining cell survival during microbial fermentation. A typical example is hydrogen production by an in vitro biosystem proposed by Zhang [14]. Undoubtedly, hydrogen would be the best energy carrier for the transportation sector in the future because of its high-energy utilization efficiency through fuel cells and nearly zero pollution for end users [16,27]. Hydrogen can be produced by chemical catalysis, biocatalysis, and combination of both. Natural and genetically modified hydrogen-producing microbes cannot produce hydrogen at yields of more than four moles of hydrogen per mol of glucose, called the Thauer limit $[28,29]$. However, an in vitro biosystem containing 13 enzymes can produce $12 \mathrm{~mol}$ of hydrogen from $1 \mathrm{~mol}$ of glucose unit, or $10 \mathrm{~mol}$ of hydrogen from $1 \mathrm{~mol}$ of xylose unit. The substrate for hydrogen production can be glucan polymers, disaccharides (sucrose, cellobiose, etc.), glucose, fructose, xylose, and so on (Fig. 1). These in vitro biosystems can be divided into four parts: (1) hydrogen production by hydrogenase from $\mathrm{NAD}(\mathrm{P}) \mathrm{H}$; (2) NAD $(\mathrm{P}) \mathrm{H}$ generation by action of two dehydrogenases on glucose 6-phosphate; (3) regeneration of glucose 6-phosphate using the enzymes from the pentose phosphate pathway, glycogenesis and glycolysis pathway; and (4) substrate modification to enter the pentose phosphate pathway, glycogenesis and glycolysis pathway. Because $\mathrm{H}_{2}$ and $\mathrm{CO}_{2}$ are gaseous products, which can be released from the aqueous phase to decrease product inhibition, the theoretical product yield can be reached. For example, the overall yields of $\mathrm{H}_{2}$ from cellobiose and xylose are 11.2 and $9.6 \mathrm{~mol}$, corresponding to $93.1 \%$ and $96 \%$ of the theoretical yields, respectively.

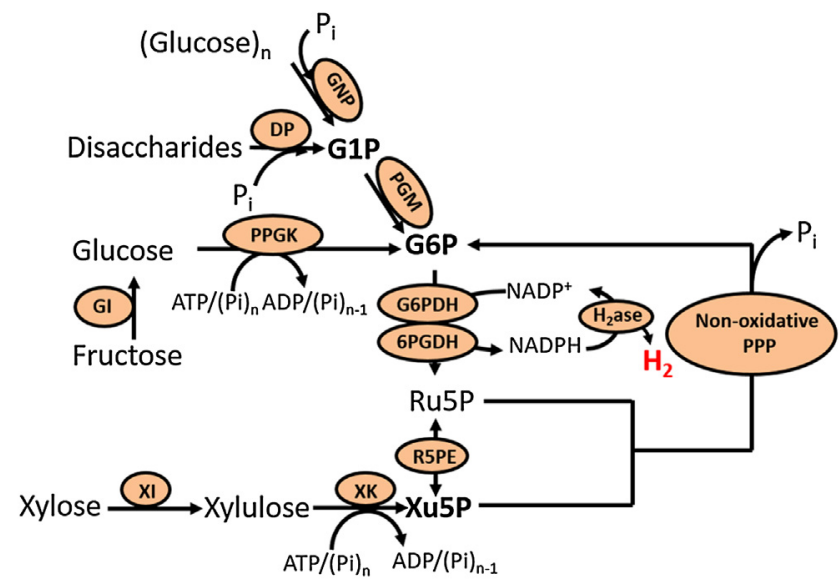

Fig. 1. Synthetic pathways for the complete conversion of various starting carbohydrates, including glucan (starch and cellulose), disaccharides (sucrose, cellobiose), glucose, fructose, and xylose, to hydrogen. PPP, pentose phosphate pathway. The enzymes are GNP, glucan phosphorylase; DP, disaccharides phosphorylase; GI, glucose isomerase; XI, xylose isomerase; PPGK, polyphosphate glucokinase; XK, xylulose kinase; PGM, phosphoglucomutase; G6PDH, G-6-P dehydrogenase; 6PGDH, 6-phosphogluconate dehydrogenase; Ru5PE, ribulose 5phosphate epimerase; and H2ase, hydrogenase. The metabolites and chemicals are G1P, glucose-1-phosphate; G6P, glucose-6-phosphate; ru5p, ribulose-5-phosphate; xu5p, xylulose-5-phosphate; and Pi, inorganic phosphate. 


\subsection{Fast reaction rates}

Because there are no cellular membranes in in vitro biosystems to limit the mass transfer, and it is easy to increase the enzyme loading or substrate loading in in vitro biosystems, in vitro biosystems always show faster reaction rates than microbial fermentation systems. Enzymatic fuel cells are an emerging electrobiochemical device that directly converts chemical energy of a variety of fuels to electricity through enzymes [30-32]. The maximum powers of enzymatic fuel cells are usually higher than those of microbial fuel cells [33]. Zhang and coworkers constructed an in vitro biosystem containing 13 enzymes as enzymatic fuel cell which can oxidize glucose completely. This biosystem is very similar to the hydrogen production system described above; the only difference is replacement of hydrogenase with diaphorase and vitamin $\mathrm{K}_{3}\left(\mathrm{VK}_{3}\right)$ for the generation of 2 electrons per NAD(P)H molecule. The maximum power output of this enzymatic fuel cell were up to $8.5-24 \mathrm{~mW} \mathrm{~cm}^{-2}$ [34,35], which are higher than those of the best microbial fuel cells, which were about $0.69-0.79 \mathrm{~mW} \mathrm{~cm}^{-2}$ [36]. The energy storage density of this enzymatic fuel cell with $15 \%\left(\mathrm{wt} / \mathrm{v}\right.$ ) maltodextrin can reach $596 \mathrm{Ah} \mathrm{kg}^{-1}$, which is one order of magnitude higher than that of lithium ion batteries. With such high power density and energy density, sugar-powered biobatteries can serve as next-generation green power sources, particularly for portable electronics. However, because sugar-powered biobatteries are an in vitro biosystem, they face the same problems as other in vitro biosystems, such as enzyme and cofactor stability and enzyme production. Enzymes have much larger catalytic volume or mass to their turnover number than the metal catalysts in the traditional cells, leading to a lower power density generated from the enzyme-catalyzed biobattery than lithium-ion battery. Enzymes are not as stable as metal catalysts, resulting in a lifetime of hours to days of the biobattery, much less than that of lithiumion battery. Much effort will be needed to address these two issues, including discovering novel enzymes, engineering enzymes, using new biomimetic cofactors, improving enzyme formulations, and optimizing biobattery configurations. This needs synergetic performance from different areas such as nanotechnology, synthetic biology, and material science. The challenges of in vitro biosystems will be discussed carefully in Section 4 .

\subsection{High tolerance in toxic environments}

Because enzymes are generally better able to tolerate toxic compounds and products than microorganisms, many in vitro biosystems can work in toxic environments that microbes cannot survive. For example, Zhang and coworkers coupled xylitol production from xylose and NADPH generation system together [37]. This in vitro biosystem can work in the presence of diluted acid-pretreated biomass hydrolysate, which is toxic to fermentative organisms, suggesting that the enzyme cocktails do not require high-purity substrates for biotransformation.

Another example is isobutanol production from glucose [23]. Sieber and coworkers designed an ATP-free pathway to produce pyruvate from glucose with $2 \mathrm{NADH}$ molecules per glucose molecule; pyruvate could then be converted to ethanol and isobutanol as shown in Fig. 2, consuming the $2 \mathrm{NADH}$ molecules per ethanol and isobutanol molecule. In a solvent tolerance test, butanol production by this in vitro biosystem containing nine enzymes was not significantly affected by the presence of up to $4 \%(\mathrm{v} / \mathrm{v})$ isobutanol, whereas even $1 \%(\mathrm{v} / \mathrm{v})$ isobutanol generally stops microbial butanol production because of the loss of membrane integrity [38].

\subsection{Highly engineering flexibility}

Compared to the complexity of microbial fermentation system, in vitro biosystems can be easily modified or engineered to improve the system performance. For example, Panke and colleagues devised an in vitro biosystem for the production of dihydroxyacetone phosphate (DHAP) production from glucose [39]. By deleting triose-phosphate isomerase in glycolysis pathway from the extract source strain to enable the accumulation of DHAP, the concentration of DHAP can reach up to $12 \mathrm{mM}$, a feat never achieved by microbial fermentation systems. Because DHAP is an unstable molecule, the addition of butanal and rabbit muscle aldolase directly to this system converted DHAP to a more stable form. This example showcases the freedom of design by modifying the genome of the host strain and by addition or removal of catalysts and/or reagents to directly influence the reaction systems. In another example, the yield of fructose produced from starch can be significantly improved by different enzyme selection. Fructose is the sweetest monosaccharide. The average annual consumption of HFCS by a person in the USA is approximately $20 \mathrm{~kg}$. Fructose is produced from starch through two steps of enzymatic conversion: (1) the starting material starch is hydrolyzed with amylase and glucoamylase to generate glucose and (2) glucose is converted to fructose by xylose isomerase. The limitation of this process is that the second step is reversible, causing the reaction to be dominated by the glucose-fructose equilibrium constant (the molar ratio of glucose to fructose at equilibrium is approximately 45:55) (Fig. 4); therefore, the fructose yield cannot be very high. To solve this issue, Benner and coworkers designed an in vitro biosystem containing (1) glucan phosphorylase (GNP), (2) phosphoglucomutase (PGM), (3) phosphoglucose isomerase (PGI), and (4) fructose-6-phosphatase (F6Pase) [40]. In the last step, the hydrolysis of fructose 6-phosphate to fructose is irreversible and exergonic, and this last enzyme converts all the intermediates to the desired product, resulting in high product yield. This pathway design illustrates the general idea that the last step of the pathway should be irreversible when designing multistep in vitro biosystems to improve product yield.

\subsection{Implement biostransformations that cannot be done by microbial fermentation}

One of the most important advantages of in vitro biosystems over microbial fermentation is the potential to implement biotransformations that can be very difficult to be catalyzed by living microbes or chemical catalysts. For example, a mixture of intracellular and extracellular enzymes in one pot can convert $\beta$-1,4-glucosidic bond-linked cellulose to $\alpha$-1,4-glucosidic bondlinked starch [41]. The conversion of cellulose to starch was achieved by four enzymes: (1) hydrolysis of cellulose to cellobiose catalyzed by an optimized cellulase cocktail containing endoglucanase and cellobiohydrolase; (2) cellobiose hydrolysis mediated by cellobiose phosphorylase (CBP) to generate glucose 1-phosphate and glucose. (3) generation of amylose from glucose 1-phosphate potato alpha-glucan phosphorylase (PGP); and (4) removal of glucose by yeast to release the product inhibition of CBP (Fig. 3). Different alpha-glucan phosphorylases have different preferences on starch with different degrees of polymerization. Three alphaglucan phosphorylases from potato and two thermophilic bacteria, Clostridium thermocellum and Thermotoga maritima, were tested for starch synthesis. Only PGP can extend the degree of polymerization of starch to several hundreds, and the other two alpha-glucan phosphorylases cannot synthesize starch with such high degree of polymerization. In this process, all glucan units in cellulose can be utilized to produce amylose, ethanol, and/or yeast single protein without sugar loss. Synthetic amylose produced from 


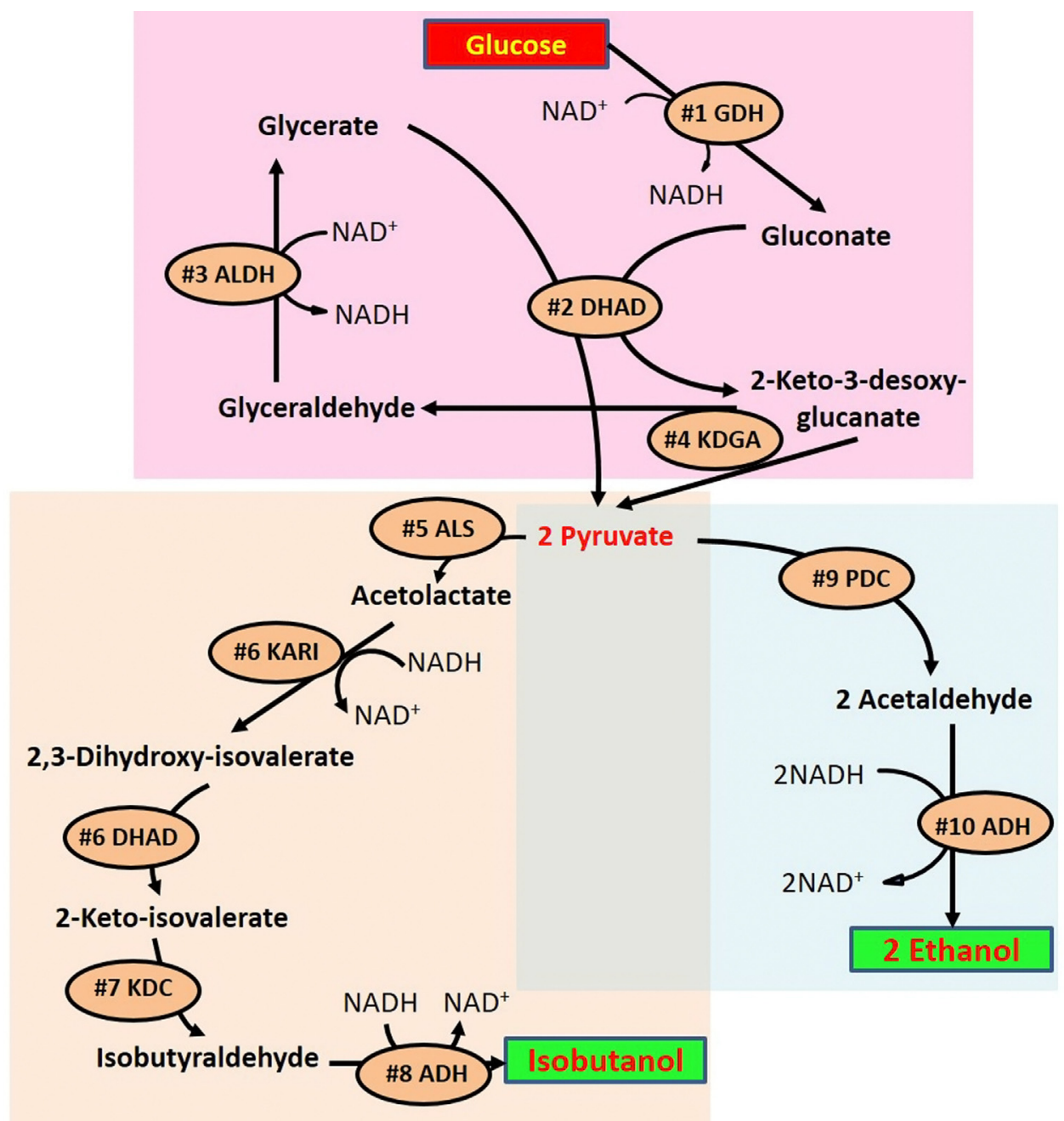

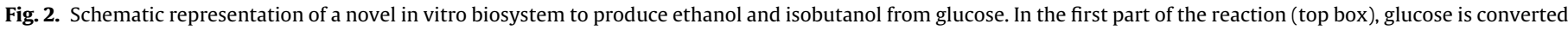

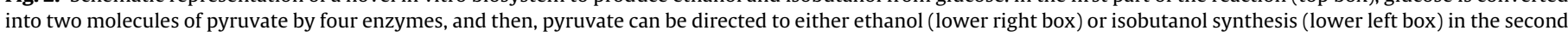

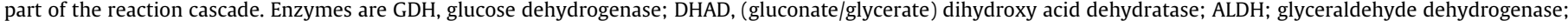

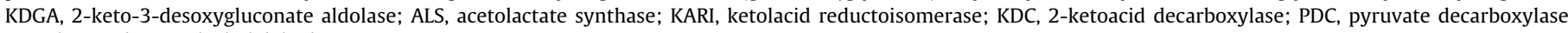
complex; and $\mathrm{ADH}$, alcohol dehydrogenase.

cellulose can have several applications, such as a healthy food additive to decrease risks of obesity and diabetes, a precursor of biodegradable plastics, and unlimited food and feed sources [42]. The cost-effective transformation of nonfood cellulose to synthetic starch could revolutionize agriculture and reshape the bioeconomy while maintaining biodiversity, minimizing agriculture's environmental footprint, and conserving freshwater [43,44].

\section{Economic analysis of in vitro biosystems for biomanufacturing}

In vitro synthetic biosystems for biomanufacturing can be regarded as a two-step biotransformation: (i) the production of numerous enzymes by whole-cell fermentation followed by the purification and (ii) in vitro biotransformation mediated by enzyme cocktails in one pot. The total cost of in vitro biosystems can be attributed to feed stock cost, enzyme and coenzyme (cofactor) cost, product titer and volumetric productivity, capital expenditures (CapEx), and operating expenses (OpEx) including separation. The product cost of in vitro biosystems is mainly based on the enzyme cost, because the cost range for enzymes, which is determined by the enzyme production cost and enzyme stability, can be much higher than other factors. Enzyme production cost is determined by the soluble protein expression level of enzyme. For example, if the targeted protein accounts for $>30 \%$ of the total soluble cellular protein of Escherichia coli, the production costs of recombinant proteins are expected to be approximately US $\$ 500 / \mathrm{kg}$, a conservative value [26]; enzyme stability can be determined by the total turnover number $\left(\mathrm{TTN}_{\mathrm{w}}\right.$, calculated as kilograms of product per kilogram of enzyme before the enzyme is dead). $\mathrm{TTN}_{\mathrm{w}}$ of the enzymes $>5000$ indicates that the enzyme cost is negligible ( $\sim 0.1 / \mathrm{kg}$ of product). For some in vitro biosystems that need coenzymes such as NAD, the $\mathrm{TTN}_{\mathrm{w}}$ of coenzymes also determines the production cost of the desired product. Biomimetic coenzymes are much more stable and cheaper than natural coenzymes; it is therefore important to replace natural high-cost and labile coenzymes with biomimetic coenzymes to decrease the product cost $[18,26]$.

\section{Problems and solutions}

Despite many proof-of-concept in vitro biosystems have been developed at the laboratory scale, large-scale implementation of in vitro biosystems for manufacturing requires synergistic efforts in enzyme engineering and discovery, enzyme production and purification, bioinformatics, bioprocess engineering, organic chemistry, etc. Many barriers, including high cost of enzyme, cofactor sta- 


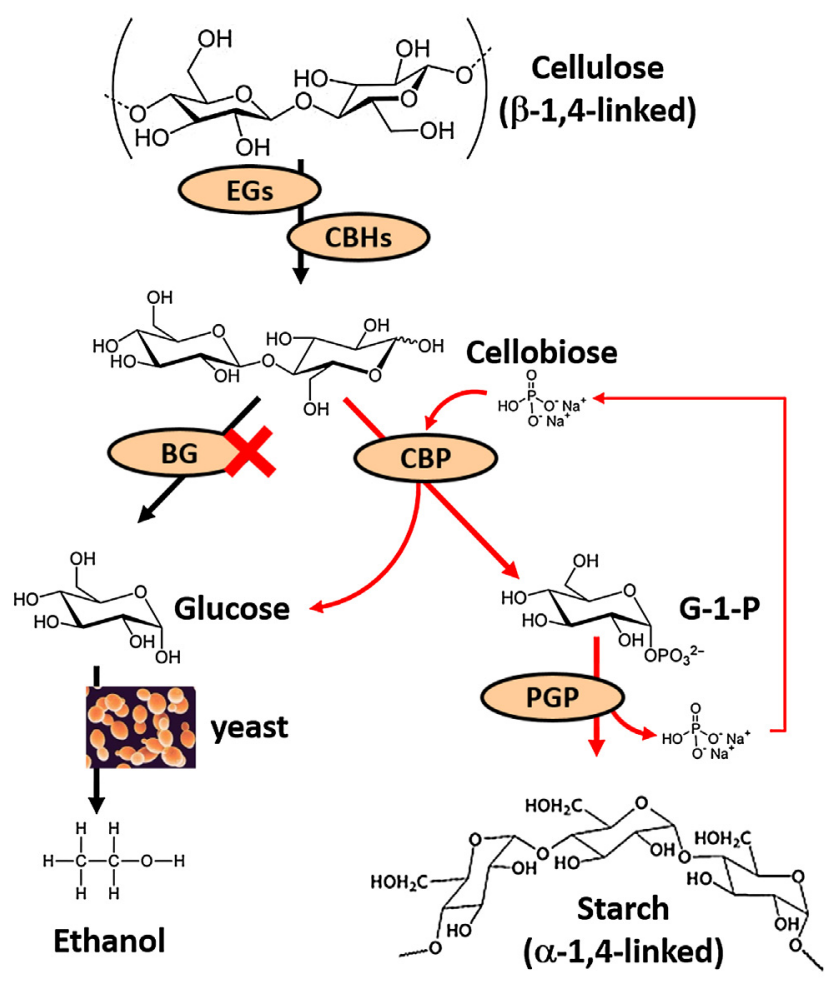

Fig. 3. In vitro biosystem for converting cellulose to starch by endoglucanases (EGs), cellobiohydrolases ( $\mathrm{CBHs}$ ), cellobiose phosphorylase (CBP), and potato alpha-glucan phosphorylase (PGP), and the residual glucose was metabolized by yeast to produce ethanol. $\beta$-glucosidase (BG) was not included in this system to avoid the generation of glucose from cellobiose.

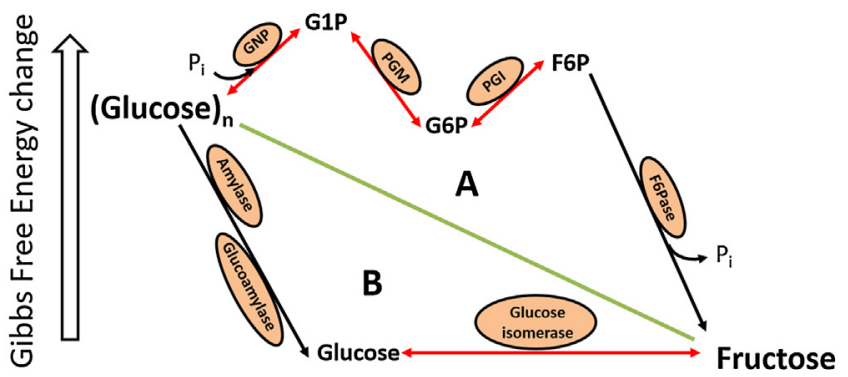

Fig. 4. Schematic representation of the production of fructose from starch by two pathways. A. The starch phosphorylation pathway for the complete fructose conversion, $\mathrm{B}$. The glucose isomerization pathway.

bility and regeneration, pathway optimization, and modeling, are remaining for the scale-up of in vitro biosystems.

\subsection{Enzyme production and purification}

As mentioned above, enzyme production is the key point for the commercialization of in vitro biosystems. At the beginning, enzyme production was always performed in the native organisms grown in certain environment for the enrichment of targeted enzymes. There are still some enzymes produced by this method now, such as overproduction of thermostable hydrogenase in Pyroccus furiosus [45]. Currently, most of the enzymes are expressed and purified in a recombinant form, using bacterial, fungal, and yeast platforms; this method is preferred because of in-depth knowledge of the organisms, ease of genetic manipulation, and high expression level [46]. The cost of protein production is highly related to its expression level. The higher the expression level, the lower is the cost of protein production [47]. Codon usage optimization is the most used method to enhance recombinant protein expression levels. For example, more than 500-fold improvement in the expression of soluble Thermotoga maritima 6PGDH has been achieved in E. coli by codon usage optimization, accounting for $>30 \%$ of the total cellular protein yield [48]. It is expected that current costs of recombinant proteins produced by E. coli BL21 are approximately US \$50-500 per kilogram of dry protein, including materials cost, labor cost, and capital depreciation based on the enzyme expression level [49]. When enzyme production is scaled up, the production costs would decrease further.

The high selling prices of enzymes manufactured by Sigma gives us an impression that the enzymes are too costly for use in large scale. The purity of commercial enzymes is relatively high. However, in vitro biosystems can use enzymes of relatively low purity as building blocks, and even cell extract can be used for in vitro biosystems such as cell-free protein synthesis [50]. Several low-cost scalable protein purification methods are available and have been developed, instead of using costly chromatographic separation methods, for example, one-step protein adsorption/desorption, purification, and immobilization by low-cost cellulosic materials [51-54], ammonia sulfate precipitation [55], and heat precipitation of thermostable enzymes [56]. Thermostable enzymes are promising building blocks for in vitro biosystems owing to the operational stability and low risk of contamination [57]. It is reported that the recombination enzyme product of thermophilic gene expressed in mesophilic hosts (such as E. coli) can retain their resistance to heat, while endogenous proteins cannot. Therefore, for highly thermophilic enzymes expressed by E. coli, high-density bacterial expression combined with heat precipitation could be the simplest way to obtain a large amount of purified proteins from $E$. coli cell extracts $[48,58]$. After cell disruption, heat treatment, and centrifugation, only soluble thermostable target enzymes remain in the supernatant. This method allows for the large-scale partial purification of thermostable enzymes expressed in E. coli. Honda and coworkers coexpressed nine thermophilic enzymes in one E. coli cell. After heat precipitation, the supernatant was used for the one-pot biotransformation directly [59]. For the recombinant thermophilic enzymes expressed in mesophilic cells, high selective whole-cell catalysts can be readily prepared compared to purified enzymes [60], because insoluble cells can be much easier collected than soluble enzymes. Honda et al. treated the E. coli cells having the thermophilic enzyme with glutaraldehyde to prevent the heatinduced leakage of the enzyme, and the resulting cells can be used as whole-cell catalyst in repeated and continuous reactions [60]. In another study, Honda et al. demonstrated the rational combination of the thermophilic whole-cell catalysts enables the construction of in vitro biosystems for the production of value-added chemicals [61].

\subsection{Enzyme stability}

As introduced in Section 3, weight-based $\mathrm{TTN}_{\mathrm{w}}$ can be regarded as the thermostability of enzymes. If $\operatorname{TTN}_{\mathrm{W}}>10^{6}$, the fraction of the enzyme cost will be less than $1 \%$ during manufacturing by in vitro biosystems [18,26,62].

In general, enzyme deactivation can be addressed by using thermoenzymes, enzyme immobilization, protein engineering through directed evolution and rational design, and their combination [18]. The discovery and utilization of thermoenzymes may be the simplest strategy. With the boosting of genome sequencing projects, several whole-genome sequences from thermophilic sources such as T. maritima, Thermus thermophilus, C. thermocellum, and Geobacillus spp., were identified. A total of 1685 clones of $T$. thermophilus HB8 are available from RIKEN DNA bank (http://dna.brc.riken.jp/ en/thermus_en.html). Therefore, it is easy to obtain a thermophilic 
gene. During the past several years, Zhang's laboratory has produced a number of thermophilic enzymes in E. coli, such as $C$. thermocellum cellodextrin phosphorylase (CthCDP) [63], C. thermocellum cellobiose phosphorylase (CthCBP) [63], C. thermocellum glucan phosphorylase (CthGP) [64], C. thermocellum PGM [65], T. maritima 6-phosphogluconate dehydrogenase [48], T. maritima fructose bisphosphatase [66], and T. maritima pentose phosphate isomerase [58]. Most of these enzymes have $\operatorname{TTN}_{\mathrm{W}}$ of $>10^{7}$ at their sub-optimal temperatures.

When a special enzyme is available only from a mesophilic source or activity modification is desired, the next tool often used is enzyme engineering involving rational design, directed evolution, or their combination $[67,68]$. The most powerful enzyme engineering method is directed evolution, which does not need the background knowledge of target enzymes [67]. In this process, the typical way is using error-prone PCR for random mutagenesis. Next, a selection or screening method identifies the better mutants, which are sequenced and often undergo one or more artificial evolution processes, including site-directed mutagenesis [69-71]. An appropriate selection/screening method is crucial for the success of directed evolution. Rational design is another alternative to improve the properties of the enzymes when an in-depth knowledge of the target enzymes is available, including catalytic mechanism and crystal structure [72-74].

Enzyme immobilization techniques, including physical adsorption, covalent binding, and cross-linked enzyme aggregates, have been used to prolong the lifetime of enzymes [75-78]. For instance, one-step protein purification and immobilization method has been developed by using low-cost, ultrahigh adsorption capacity regenerated amorphous cellulose (RAC) to adsorb carbohydrate binding module (CBM)-tagged thermophilic $C$. thermocellum PGI [54]. The resulting immobilized PGI has about two-fold higher activity than non-immobilized PGI and has about 80 -fold higher stability than non-immobilized PGI at $0.001 \mathrm{mg} / \mathrm{ml}$ enzyme concentration. Another example is that immobilized glucose isomerase has a working lifetime of up to 2 years at $55^{\circ} \mathrm{C}$ [79]. Despite the disadvantage that immobilization procedures often inactivate some percentages of enzyme activity, easy recycle and increased stability still make immobilized enzyme much more cost-efficient than free enzymes.

\subsection{Redox enzyme engineering}

Because the cost of cofactor is high, it is critical to balance the cofactor by cost-effective cofactor regeneration systems for the in vitro biosystems to manufacture low-value commodity chemicals [62]. Some regeneration systems have been introduced into in vitro biosystems to maintain the concentration of the cofactors such as NADH, NADPH, and ATP. Formate and formate dehydrogenase are the most used NADH regeneration systems, because the product of formate oxidation is carbon dioxide [80]. Bowie and coworkers proposed a promising approach for the construction of a synthetic purge valve module to achieve an intra pathway redox balance of NADPH [81]. Several ATP regeneration systems have been constructed using glucose and pyruvate, instead of a compound with a high-energy phosphate bond [82-84]. However, the instability of cofactors such as NAD and NADP limits the commercial viability of in vitro biosystems for low-value products. Honda and coworkers proposed an in vitro biosystem containing eight enzymes for the salvage synthesis of $\mathrm{NAD}^{+}[85]$. Although this method requires several enzymes for the industrial purpose only to resynthesize $\mathrm{NAD}^{+}$, the best solution is the replacement of natural cofactors with low-cost biomimetic cofactors [38,86]. Biomimetic cofactors such as nicotinamide mononucleotide (NMN) and 1-benzyl-3-carbamoyl-pyridinium (BCP) are not only economical, but they also have much better stability $[38,87]$. NMN is a precursor of $\mathrm{NAD}(\mathrm{P})$ and is much smaller in size than $\mathrm{NAD}(\mathrm{P})$ (Fig. 5). A few wild-type redox enzymes function using NMN, including liver alcohol dehydrogenase [88] and glutamic dehydrogenase [89]. Recently, Scott et al. have shown that engineered P. furiosus alcohol dehydrogenase can work on NMN [90]. Fish et al. found that the pyrophosphate and adenosine groups in $\mathrm{NAD}(\mathrm{P})$ are not essential for the hydride transfer and proposed the use of BCP chloride to replace $N A D(P)[91]$. Clark and Fish collaborated to show that an engineered P450 mutant with two amino acid changes can utilize BCP [92]. Furthermore, another group showed that engineered P450 can utilize $\mathrm{Zn}$ dust as an electron source rather than natural cofactors [93,94]. In 2012, a large international group showed that wild-type enoate reductases can work with both BCP and 1-buta-3-carbamoyl-pyridinium (BuCP) [95]. In 2011, Zhao and coworkers presented a bio-orthogonal system that catalyzed the oxidative decarboxylation of L-malate with a dedicated biomimetic cofactor, nicotinamide flucytosine dinucleotide, where the redox enzymes were engineered using site-saturation mutagenesis of the key amino acid sites [96].

Although the importance of redox enzyme engineering is increasingly recognized for the future biomanufacturing [25,26,97], redox enzyme engineering remains in its early stage, because no framework or general rules exist for engineering redox enzymes on non-natural cofactors [90]. This direction may become among the top R\&D priorities of in vitro biosystems, including cofactors, especially for the production of low-value biocommodities.

\subsection{The determination of reaction conditions}

In vitro biosystems require all enzymes to have activity under one condition $[14,63]$. The simplest way is choosing the optimized condition for the rate-limiting enzymes, and then, on the basis of the enzyme activity of these enzymes under the optimized condition, add other enzymes with the same activity to the reaction systems. The relative simplicity of in vitro biosystems makes them much easier to construct a kinetic model to simulate the whole process, thus maximizing the reaction rate and product yield [38]. A nonlinear kinetic model was developed to simulate enzymatic hydrogen production from cellobiose and predict rate-limiting step [63]. Ardao and Zeng used this nonlinear kinetic model incorporating 19 mass balance equations to solve a multi-objective optimization of this in vitro biosystem; one set of solutions predicted the ability of this system to retain $90 \%$ yield while increasing the reaction rate to $355 \mathrm{mmol} / \mathrm{L} / \mathrm{h}$ [98]. Later, parameters of this model were fitted with experimental data using a genetic algorithm, and a global sensitivity analysis was used to identify the enzymes that have a significant effect on reaction rate and yield. Through an optimal set of enzyme concentrations predicted by this model, volumetric hydrogen productivity was further enhanced to $32 \mathrm{mmol} / \mathrm{L} / \mathrm{h}$, that is, by threefold, and further increased to $54 \mathrm{mmol} / \mathrm{L} / \mathrm{h}$ by increasing the reaction temperature and substrate and enzyme concentrations [99]. Ensemble Modelling for Robustness Analysis (EMRA), which was constructed by James Liao's group, was used to determine the robustness of in vitro biosystems when the enzyme amounts are changed [100,101]. This method could be a valuable tool for the optimization of enzyme ratios in in vitro biosystems without a priori knowledge of specific enzyme parameter values.

\subsection{Scale-up}

The scale-up of microbial fermentation processes is complicated that can lead to unpredictable process performance, because reaction scale affects molecular diffusion, gas transfer, hydrostatic pressure, mixing rates, temperature gradients, $\mathrm{pH}$ effects, and other parameters $[21,102]$. There are few examples of industrial-scale 


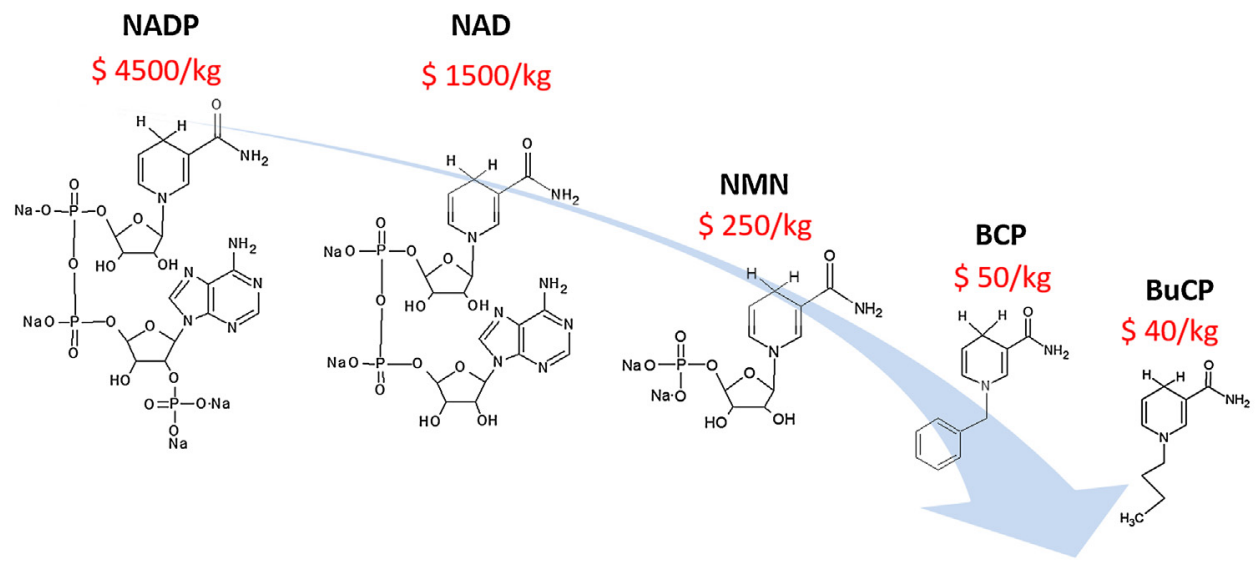

Fig. 5. Structures and costs of natural cofactors (NADP and NAD) and biomimetic cofactors (NMN, BCP, and BuCP).

production by in vitro biosystems containing more than 4 enzymes; to our limited knowledge, the only two successful examples are cell-free protein synthesis for aglycosylated antibodies ( $5 \mathrm{~L}$ scale) [103] and cytokines (100 L scale) [104], and protein yields from the microliter to liter scale is linear. Therefore, the scale-up of in vitro biosystems is similar to that of chemical industry, unlike microbial fermentation. It is believed that the success of the first in vitro biosystem for large-scale biomanufacturing in the next several years will clarify its industrial feasibility [18].

\section{Principle of designing in vitro biosystems for biomanufacturing}

The aim of the design of in vitro biosystems should be focused on commercial feasibility, several aspects should be taken into account, (1) It is very important that the cost of products should be higher than that of substrates. (2) The product cost is mainly attributed to the enzyme cost. Therefore, all the enzymes should have a high $\operatorname{TTN}_{\mathrm{w}}$ to minimize the enzyme cost, these enzymes should have high soluble protein expression levels in recombinant host cells, and the condition of the reaction should be optimized to maintain the enzyme activity and stability. (3) It is better to not involve cofactors in these in vitro biosystems; if the cofactor cannot be avoided, it should be balanced by adding new components to prolong the reaction time and reduce the product cost, especially for the low-cost product. It is much better to replace the natural cofactors with biomimetic cofactors. (4) The last step should be irreversible to maximize the product yield or the product can be removed in situ.

\section{Conclusion}

Compared with the predominant microbial fermentation on manufacturing, in vitro biosystems for manufacturing is still at the early stage. With the development of the more stable enzymes as standardized building blocks and the improvements in redox enzyme engineering to work with less costly and more stable biomimetic cofactors, in vitro biosystems will eventually become a new biotechnology platform for biomanufacturing numerous products, parallel to microbial fermentation platform.

\section{Acknowledgments}

This study was supported partially by the 1000 -youth program of China and Tianjin Municipal Science and Technology Commission (11ZCZDSY0840).

\section{References}

[1] E. Buchner, Alkoholische Gärung ohne Hefezellen (Vorläufige Mitteilung), Ber. Dtsch. Chem. Ges. 30 (1897) 117-124.

[2] A. Harden, W.J. Young, The alcoholic ferment of yeast-juice, Proc. R. Soc. Lond. 77B (1907) 405-422.

[3] O.H. Warburg, Über den Stoffwechsel der Tumoren, Springer, Berlin, 1926.

[4] C.F. Cori, Mammalian carbohydrate metabolism, Physiol. Rev. 11 (1931) $143-275$.

[5] G.T. Cori, C.F. Cori, The formation of hexosephosphate esters in frog muscle, J. Biol. Chem. 116 (1936) 119-128.

[6] H.A. Krebs, L.V. Eggleston, Metabolism of acetoacetic acid in animal tissues, Nature 154 (1944) 209-210.

[7] M. Calvin, A.A. Benson, The path of carbon in photosynthesis, Science 107 (1948) 476-480.

[8] M.W. Nirenberg, J.H. Matthaei, The dependence of cell-free protein synthesis in E. coli upon naturally occurring or synthetic polyribonucleotides, Proc. Natl. Acad. Sci. U. S. A. 47 (1961) 1588-1602.

[9] S.H. Bhosale, M.B. Rao, V.V. Deshpande, Molecular and industrial aspects of glucose isomerase, Microbiol. Rev. 60 (1996) 280-300.

[10] R. Saiki, D. Gelfand, S. Stoffel, S. Scharf, R. Higuchi, G. Horn, K. Mullis, H. Erlich, Primer-directed enzymatic amplification of DNA with a thermostable DNA polymerase, Science 239 (1988) 487-491.

[11] H. Yamada, M. Kobayashi, Nitrile hydratase and its application to industrial production of acrylamide, Biosci. Biotechnol. Biochem. 60 (1996) 1391-1400.

[12] P. Michels, J. Rosazza, The evolution of microbial transformations for industrial applications, SIM News 2009 (2009) 36-52.

[13] Y. Xu, S. Masuko, M. Takieddin, H. Xu, R. Liu, J. Jing, S.A. Mousa, R.J. Linhardt, J. Liu, Chemoenzymatic synthesis of homogeneous ultralow molecular weight heparins, Science 334 (2011) 498-501.

[14] Y.-H.P. Zhang, B.R. Evans, J.R. Mielenz, R.C. Hopkins, M.W.W. Adams, High-yield hydrogen production from starch and water by a synthetic enzymatic pathway, PLoS One 2 (2007) e456.

[15] J.K. Guterl, D. Garbe, J. Carsten, F. Steffler, B. Sommer, S. Reisse, A. Philipp, M. Haack, B. Ruhmann, A. Koltermann, U. Kettling, T. Bruck, V. Sieber, Cell-free metabolic engineering: production of chemicals by minimized reaction cascades, ChemSusChem 5 (2012) 2165-2172.

[16] R.M. Navarro, M.A. Peña, J.L.G. Fierro, Hydrogen production reactions from carbon feedstocks: fossil fuels and biomass, Chem. Rev. 107 (2007) 3952-3991.

[17] D.F. Savage, J. Way, P.A. Silver, Defossiling fuel: how synthetic biology can transform biofuel production, ACS Chem. Biol. 3 (2008) 13-16.

[18] Y.-H.P. Zhang, Production of biofuels and biochemicals by in vitro synthetic biosystems: opportunities and challenges, Biotechnol. Adv. 33 (2015) 1467-1483.

[19] A.L. Demain, Pickles, pectin, and penicillin, Annu. Rev. Microbiol. 58 (2004) $1-42$.

[20] X. Zhang, K. Jantama, J.C. Moore, K.T. Shanmugam, L.O. Ingram, Production of L -alanine by metabolically engineered Escherichia coli, Appl. Microbiol. Biotechnol. 77 (2007) 355-366.

[21] Q.M. Dudley, A.S. Karim, M.C. Jewett, Cell-free metabolic engineering: biomanufacturing beyond the cell, Biotechnol. J. 10 (2015) 69-82.

[22] S. Rupp, Next-generation bioproduction systems: cell-free conversion concepts for industrial biotechnology, Eng. Life Sci. 13 (2013) 19-25.

[23] J.-K. Guterl, D. Garbe, J. Carsten, F. Steffler, B. Sommer, S. Reiße, A. Philipp, M. Haack, B. Rühmann, A. Koltermann, U. Kettling, T. Brück, V. Sieber, Cell-free metabolic engineering: production of chemicals by minimized reaction cascades, ChemSusChem 5 (2012) 2165-2172.

[24] J.R. Swartz, Transforming biochemical engineering with cell-free biology, AIChE J. 58 (2012) 5-13. 
[25] Y.H.P. Zhang, Simpler is better: high-yield and potential low-cost biofuels production through cell-free synthetic pathway biotransformation (SyPaB), ACS Catal. 1 (2011) 998-1009.

[26] Y.-H.P. Zhang, Production of biocommodities and bioelectricity by cell-free synthetic enzymatic pathway biotransformations: challenges and opportunities, Biotechnol. Bioeng. 105 (2010) 663-677.

[27] R.D. Cortright, R.R. Davda, J.A. Dumesic, Hydrogen from catalytic reforming of biomass-derived hydrocarbons in liquid water, Nature 418 (2002) 964-967.

[28] K. Thauer, K. Jungermann, K. Decker, Energy conservation in chemotrophic anaerobic bacteria, Bacteriol. Rev. 41 (1977) 100-180.

[29] T. Maeda, V. Sanchez-Torres, T.K. Wood, Hydrogen production by recombinant Escherichia coli strains, Microbiol. Biotechnol. (2012), http:// dx.doi.org/10.1111/j.1751-7915.2011.00282.x.

[30] Z. Zhu, Y. Wang, S.D. Minteer, Y.H. Percival Zhang, Maltodextrin-powered enzymatic fuel cell through a non-natural enzymatic pathway, J. Power Sources 196 (2011) 7505-7509.

[31] S.C. Barton, J. Gallaway, P. Atanassov, Enzymatic biofuel cells for implantable and microscale devices, Chem. Rev. 104 (2004) 4867-4886.

[32] M.J. Moehlenbrock, S.D. Minteer, Extended lifetime biofuel cells, Chem. Soc. Rev. 37 (2008) 1188-1196.

[33] M.H. Osman, A.A. Shah, F.C. Walsh, Recent progress and continuing challenges in bio-fuel cells. Part I: enzymatic cells, Biosens. Bioelectron. 26 (2011) 3087-3102.

[34] W. Gellett, J. Schumacher, M. Kesmez, D. Le, S.D. Minteer, High current density air-breathing laccase biocathode, J. Electrochem. Soc. 157 (2010) B557-B562.

[35] A. Zebda, C. Gondran, A. Le Goff, M. Holzinger, P. Cinquin, S. Cosnier, Mediatorless high-power glucose biofuel cells based on compressed carbon nanotube-enzyme electrodes, Nat. Commun. 2 (2011) 370.

[36] B.E. Logan, Exoelectrogenic bacteria that power microbial fuel cells, Nat. Rev. Microbiol. 7 (2009) 375-381.

[37] Y. Wang, W.D. Huang, N. Sathitsuksanoh, Z. Zhu, Y.-H.P. Zhang, Biohydrogenation from biomass sugar mediated by in vitro synthetic enzymatic pathways, Chem. Biol. 18 (2011) 372-380.

[38] J.A. Rollin, T.K. Tam, Y.-H.P. Zhang, New biotechnology paradigm: cell-free biosystems for biomanufacturing, Green Chem. 15 (2013) 1708-1719.

[39] M. Bujara, M. Schumperli, S. Billerbeck, M. Heinemann, S. Panke, Exploiting cell-free systems: implementation and debugging of a system of biotransformations, Biotechnol. Bioeng. 106 (2010) 376-389.

[40] A. Moradian, S.A. Benner, A biomimetic biotechnological process for converting starch to fructose: thermodynamic and evolutionary considerations in applied enzymology, J. Am. Chem. Soc. 114 (1992) 6980-6987.

[41] C. You, H. Chen, S. Myung, N. Sathitsuksanoh, H. Ma, X.-Z. Zhang, J. Li, Y.-H.P. Zhang, Enzymatic transformation of nonfood biomass to starch, Proc. Natl. Acad. Sci. U. S. A. 110 (2013) 7182-7187

[42] H.-G. Chen, Y.H.P. Zhang, New biorefineries and sustainable agriculture: increased food, biofuels, and ecosystem security, Renewable Sustainable Energy Rev. 47 (2015) 117-132.

[43] C. Somerville, H. Youngs, C. Taylor, S.C. Davis, S.P. Long, Feedstocks for lignocellulosic biofuels, Science 329 (2010) 790-792.

[44] Y.H.P. Zhang, Next generation biorefineries will solve the food, biofuels, and environmental trilemma in the energy-food-water nexus, Energy Sci. Eng. 1 (2013) 27-41

[45] S.K. Chandrayan, P.M. McTernan, R.C. Hopkins, J. Sun, F.E. Jenney Jr., M.W Adams, Engineering hyperthermophilic archaeon Pyrococcus furiosus to overproduce its cytoplasmic [NiFe]-hydrogenase, J. Biol. Chem. 287 (2012) 3257-3264

[46] A.L. Demain, P. Vaishnav, Production of recombinant proteins by microbes and higher organisms, Biotechnol. Adv. 27 (2009) 297-306

[47] C. You, Y.H.P. Zhang, Cell-Free Biosystems for Biomanufacturing, In: J.-J Zhong (Ed.), Adv. Biochem. Eng. Biotechnol., Springer Berlin Heidelberg (2013), 89-119.

[48] Y. Wang, Y.-H.P. Zhang, Overexpression and simple purification of the Thermotoga maritima 6-phosphogluconate dehydrogenase in Escherichia coli and its application for NADPH regeneration, Microb. Cell Fact. 8 (2009) 30.

[49] P.r. Tufvesson, J. Lima-Ramos, M. Nordblad, J.M. Woodley, Guidelines and cost analysis for catalyst production in biocatalytic processes, Org. Proc. Res. Dev. 15 (2011) 266-274

[50] Y. Wang, Y.-H.P. Zhang, Cell-free protein synthesis energized by slowly-metabolized maltodextrin, BMC Biotechnol. 9 (2009) 58.

[51] J. Hong, Y. Wang, X. Ye, Y.-H.P. Zhang, Simple protein purification through affinity adsorption on regenerated amorphous cellulose followed by intein self-cleavage, J. Chromatogr. A 1194 (2008) 150-154.

[52] J. Hong, X. Ye, Y. Wang, Y.-H.P. Zhang, Bioseparation of recombinant cellulose binding module-protein by affinity adsorption on an ultra-high-capacity cellulosic adsorbent, Anal. Chim. Acta 621 (2008) 193-199.

[53] H.H. Liao, S. Myung, Y.-H.P. Zhang, One-step purification and immobilization of thermophilic polyphosphate glucokinase from Thermobifida fusca YX: glucose-6-phosphate generation without ATP, Appl. Microbiol. Biotechnol. 93 (2012) 1109-1117.

[54] S. Myung, X.-Z. Zhang, Y.-H.P. Zhang, Ultra-stable phosphoglucose isomerase through immobilization of cellulose-binding module-tagged thermophilic enzyme on low-cost high-capacity cellulosic adsorbent, Biotechnol. Prog. 27 (2011) 969-975.
[55] Y.-H.P. Zhang, J.R. Mielenz, Renewable hydrogen carrier-carbohydrate: constructing the carbon-neutral carbohydrate economy, Energies 4 (2011) 254-275.

[56] F. Sun, X. Zhang, S. Myung, Y.H.P. Zhang, Thermophilic Thermotoga maritima ribose-5-phosphate isomerase RpiB: optimized heat treatment purification and basic characterization, Protein Expr. Purif. 82 (2012) 302-307.

[57] P. Turner, G. Mamo, E.N. Karlsson, Potential and utilization of thermophiles and thermostable enzymes in biorefining, Microb. Cell Fact. 6 (2007) 9.

[58] F.F. Sun, X.Z. Zhang, S. Myung, Y.-H.P. Zhang, Thermophilic Thermotoga maritima ribose-5-phosphate isomerase RpiB: Optimized heat treatment purification and basic characterization, Protein Expr. Purif. 82 (2012) 302-307.

[59] P.H. Ninh, K. Honda, T. Sakai, K. Okano, H. Ohtake, Assembly and multiple gene expression of thermophilic enzymes in Escherichia coli for in vitro metabolic engineering, Biotechnol. Bioeng. (2014).

[60] P.H. Ninh, K. Honda, Y. Yokohigashi, K. Okano, T. Omasa, H. Ohtake, Development of a continuous bioconversion system using a thermophilic whole-cell biocatalyst, Appl. Environ. Microbiol. 79 (2013) 1996-2001.

[61] K. Honda, S. Maya, T. Omasa, R. Hirota, A. Kuroda, H. Ohtake, Production of 2-deoxyribose 5-phosphate from fructose to demonstrate a potential of artificial bio-synthetic pathway using thermophilic enzymes, J. Biotechnol. 148 (2010) 204-207.

[62] Y.H.P. Zhang, What is vital (and not vital) to advance economically-competitive biofuels production, Process Biochem. 46 (2011) 2091-2110.

[63] X. Ye, Y. Wang, R.C. Hopkins, M.W.W. Adams, B.R. Evans, J.R. Mielenz, Y.-H.P. Zhang, Spontaneous high-yield production of hydrogen from cellulosic materials and water catalyzed by enzyme cocktails, ChemSusChem 2 (2009) 149-152.

[64] X. Ye, J. Rollin, Y.-H.P. Zhang, Thermophilic $\alpha$-glucan phosphorylase from Clostridium thermocellum: cloning, characterization and enhanced thermostability, J. Mol. Catal. B: Enzym. 65 (2010) 110-116.

[65] Y. Wang, Y.-H.P. Zhang, A highly active phosphoglucomutase from Clostridium thermocellum: Cloning, purification, characterization, and enhanced thermostability, J. Appl. Microbiol. 108 (2010) 39-46.

[66] S. Myung, Y.R. Wang, Y.-H.P. Zhang, Fructose-1,6-bisphosphatase from a hyper-thermophilic bacterium Thermotoga maritima: characterization, metabolite stability and its implications, Proc. Biochem. 45 (2010) $1882-1887$.

[67] F.H. Arnold, A.A. Volkov, Directed evolution of biocatalyists, Curr. Opin. Chem. Biol. 3 (1999) 54-59.

[68] V.G. Eijsink, A. Bjork, S. Gaseidnes, R. Sirevag, B. Synstad, B. van den Burg, G. Vriend, Rational engineering of enzyme stability, J. Biotechnol. 113 (2004) 105-120.

[69] A.J. Ruff, A. Dennig, U. Schwaneberg, To get what we aim for: progress in diversity generation methods, FEBS J. (2013)

[70] S. Brinkmann-Chen, T. Flock, J.K.B. Cahn, C.D. Snow, E.M. Brustad, J.A McIntosh, P. Meinhold, L. Zhang, F.H. Arnold, General approach to reversing ketol-acid reductoisomerase cofactor dependence from NADPH to NADH, Proc. Natl. Acad. Sci. 110 (2013) 10946-10951.

[71] M.T. Reetz, Directed Evolution of Enzymes, Enzyme Catalysis in Organic Synthesis, Wiley-VCH Verlag GmbH \& Co. KGaA, 2012, pp. 119-190.

[72] X. Liu, D. Yao, Feed enzyme rational design and its improved technology, J. Agric. Sci. Technol. (2013) 46-52.

[73] X. Ye, C. Zhang, Y.H.P. Zhang, Engineering a large protein by combined rational and random approaches: stabilizing the Clostridium thermocellum cellobiose phosphorylase, Mol. Biosyst. 8 (2012) 1815-1823.

[74] L.G. Otten, F. Hollmann, I.W.C.E. Arends, Enzyme engineering for enantioselectivity: from trial-and-error to rational design, Trends Biotechnol. 28 (2010) 46-54.

[75] L. Cao, L.v. Langen, R.A. Sheldon, Immobilised enzymes: carrier-bound or carrier-free, Curr. Opin. Biotechnol. 14 (2003) 387-394.

[76] L. Cao, Immobilised enzymes: science or art, Curr. Opin. Chem. Biol. 9 (2005) 217-226.

[77] Y.-H.P. Zhang, S. Myung, C. You, Z.G. Zhu, J. Rollin, Toward low-cost biomanufacturing through cell-free synthetic biology: bottom-up design, J. Mater. Chem. 21 (2011) 18877-18886.

[78] M. Hartmann, D. Jung, Biocatalysis with enzymes immobilized on mesoporous hosts: the status quo and future trends, J. Mater. Chem. 20 (2010) 844-857

[79] D. Vasic-Racki, History of industrial biotransformations-dreams and realities, in: A. Liese, S. Seebald, C. Wandrey (Eds.), Industrial Biotransformations, Wiley-VCH, KGaA, Weinheim, 2006, pp. 1-37.

[80] H. Yamamoto, K. Mitsuhashi, N. Kimoto, Y. Kobayashi, N. Esaki, Robust NADH-regenerator: improved alpha-haloketone-resistant formate dehydrogenase, Appl. Microbiol. Biotechnol. 67 (2005) 33-39.

[81] P.H. Opgenorth, T.P. Korman, J.U. Bowie, A synthetic biochemistry molecular purge valve module that maintains redox balance, Nat. Commun. 5 (2014) 4113.

[82] K.A. Calhoun, J.R. Swartz, Energizing cell-free protein synthesis with glucose metabolism, Biotechnol. Bioeng. 90 (2005) 606-613.

[83] D.M. Kim, J.R. Swartz, Prolonging cell-free protein synthesis with a novel ATP regeneration system, Biotechnol. Bioeng. 66 (1999) 180-188.

[84] D.M. Kim, J.R. Swartz, Regeneration of adenosine triphosphate from glycolytic intermediates for cell-free protein synthesis, Biotechnol. Bioeng. 74 (2001) 309-316. 
[85] K. Honda, N. Hara, M. Cheng, A. Nakamura, K. Mandai, K. Okano, H. Ohtake, In vitro metabolic engineering for the salvage synthesis of $\mathrm{NAD}($.$) , Metab.$ Eng. 35 (2016) 114-120.

[86] C.E. Paul, I.W.C.E. Arends, F. Hollmann, Is simpler better: synthetic nicotinamide cofactor analogues for redox chemistry, ACS Catal. 4 (2014) 788-797.

[87] C.E. Paul, F. Hollmann, A survey of synthetic nicotinamide cofactors in enzymatic processes, Appl. Microbiol. Biot. 100 (2016) 4773-4778.

[88] B.V. Plapp, D.C. Sogin, R.T. Dworschack, D.P. Bohlken, C. Woenckhaus, R. Jeck, Kinetics and native and modified liver alcohol dehydrogenase with coenzyme analogs: isomerization of enzyme-nicotinamide adenine dinucleotide complex, Biochemistry 25 (1986) 5396-5402.

[89] H.F. Fisher, L.L. McGregor, The ability of reduced nicotinamide mononucleotide to function as a hydrogen donor in the glutamic dehydrogenase reaction, Biochem. Biophys. Res. Commun. 34 (1969) 627-632.

[90] E. Campbell, M. Meredith, S.D. Minteer, S. Banta, Enzymatic biofuel cells utilizing a biomimetic cofactor, Chem. Commun. 48 (2012) 1898-1900.

[91] H.C. Lo, C. Leiva, O. Buriez, J.B. Kerr, M.M. Olmstead, R.H. Fish, Bioorganometallic chemistry 13 . Regioselective reduction of $\mathrm{NAD}^{+}$models, 1-benzylnicotinamde triflate and beta-nicotinamide ribose-5'-methyl phosphate, with in situ generated $\left[\mathrm{Cp}^{*} \mathrm{Rh}(\mathrm{Bpy}) \mathrm{H}\right]^{+}$: structure-activity relationships, kinetics, and mechanistic aspects in the formation of the 1,4-NADH derivatives, Inorg. Chem. 40 (2001) 6705-6716.

[92] J.D. Ryan, R.H. Fish, D.S. Clark, Engineering cytochrome P450 enzymes for improved activity towards biomimetic 1,4-NADH cofactors, ChemBioChem 9 (2008) 2579-2582.

[93] J. Nazor, U. Schwaneberg, Laboratory evolution of P450 BM-3 for mediated electron transfer, ChemBioChem 7 (2006) 638-644

[94] J. Nazor, S. Dannenmann, R.O. Adjei, Y.B. Fordjour, I.T. Ghampson, M. Blanusa, D. Roccatano, U. Schwaneberg, Laboratory evolution of P450 BM3 for mediated electron transfer yielding an activity-improved and reductase-independent variant, Protein Eng. Des. Sel. 21 (2008) 29-35.

[95] C.E. Paul, S. Gargiulo, D.J. Opperman, I. Lavandera, V. Gotor-Fernández, V, Gotor, A. Taglieber, I.W.C.E. Arends, F. Hollmann, Mimicking nature: synthetic nicotinamide cofactors for CC bioreduction using enoate reductases, Org. Lett. 15 (2012) 180-183.

[96] D. Ji, L. Wang, S. Hou, W. Liu, J. Wang, Q. Wang, Z.K. Zhao, Creation of bioorthogonal redox systems depending on nicotinamide flucytosine dinucleotide, J. Am. Chem. Soc. 133 (2011) 20857-20862.

[97] Y.-H.P. Zhang, W.-D. Huang, Constructing the electricity-carbohydrate-hydrogen cycle for a sustainability revolution, Trends Biotechnol. 30 (2012) 301-306.

[98] I. Ardao, A.-P. Zeng, In silico evaluation of a complex multi-enzymatic system using one-pot and modular approaches: application to the high-yield production of hydrogen from a synthetic metabolic pathway, Chem. Eng. Sci. 87 (2013) 183-193.

[99] J.A. Rollin, J. Martin del Campo, S. Myung, F. Sun, C. You, A. Bakovic, R. Castro, S.K. Chandrayan, C.-H. Wu, M.W.W. Adams, R.S. Senger, Y.-H.P. Zhang, High-yield hydrogen production from biomass by in vitro metabolic engineering: mixed sugars coutilization and kinetic modeling, Proc. Natl. Acad. Sci. 112 (2015) 4964-4969.

[100] Y. Lee, J.G. Lafontaine Rivera, J.C. Liao, Ensemble Modeling for Robustnes Analysis in engineering non-native metabolic pathways, Metab. Eng. 25 (2014) 63-71.

[101] M.K. Theisen, J.G. Lafontaine Rivera, J.C. Liao, Stability of ensemble models predicts productivity of enzymatic systems, PLoS Comput. Biol. 12 (2016) e1004800.

[102] R. Takors, Scale-up of microbial processes: impacts, tools and open questions, J. Biotechnol. 160 (2012) 3-9.

[103] G. Yin, E.D. Garces, J. Yang, J. Zhang, C. Tran, A.R. Steiner, C. Roos, S. Bajad, S Hudak, K. Penta, J. Zawada, S. Pollitt, C.J. Murray, Aglycosylated antibodies and antibody fragments produced in a scalable in vitro transcription-translation system, MAbs 4 (2012) 217-225.

[104] J.F. Zawada, G. Yin, A.R. Steiner, J. Yang, A. Naresh, S.M. Roy, D.S. Gold, H.G. Heinsohn, C.J. Murray, Microscale to manufacturing scale-up of cell-free cytokine production-a new approach for shortening protein production development timelines, Biotechnol. Bioeng. 108 (2011) 1570-1578. 